(2) OPEN ACCESS

\title{
Survey of German medical students during the COVID-19 pandemic: attitudes toward volunteering versus compulsory service and associated factors
}

\author{
Lorenz Mihatsch, ${ }^{1}$ Mira von der Linde, ${ }^{2}$ Franziska Knolle, ${ }^{3,4}$ Benjamin Luchting, ${ }^{5}$ \\ Konstantinos Dimitriadis, ${ }^{6}$ Jens Heyn ${ }^{1}$
}

${ }^{1}$ Department of Anaesthesiology and Intensive Care Medicine, Ludwig-Maximilians-Universität München, Munich, Germany ${ }^{2}$ Department of Psychology, University of Münster, Munster, Germany

${ }^{3}$ Department of diagnostic and interventional Neuroradiology, Technical University of Munich, Munich, Germany ${ }^{4}$ Department of Psychiatry, University of Cambridge, Cambridge, UK

${ }^{5}$ Department of Pain Medicine, Landsberg am Lech Clinic, Landsberg am Lech, Germany ${ }^{6}$ Department of Neurology, Ludwig-Maximilians-Universität München, Munich, Germany

\section{Correspondence to}

Lorenz Mihatsch, Department of Anaesthesiology and Intensive Care Medicine Ludwig-Maximilians-Universität München, Munich, Germany; l.mihatsch@tum.de

Received 29 December 2020 Revised 29 April 2021 Accepted 4 May 2021
A Check for updates

(c) Author(s) (or their employer(s)) 2021. Re-use permitted under CC BY-NC. No commercial re-use. See rights and permissions. Published by BMJ.

\begin{tabular}{l}
\hline To cite: Mihatsch L, \\
von der Linde M, Knolle F, \\
et al. J Med Ethics Epub \\
ahead of print: [please \\
include Day Month Year]. \\
doi:10.1136/ \\
medethics-2020-107202
\end{tabular}

\section{ABSTRACT}

Due to the spread of COVID-19, a key challenge was to reduce potential staff shortages in the healthcare sector. Besides recruiting retired healthcare workers, medical students were considered to support this task. Commitment of medical students in Germany during the COVID-19 pandemic was evaluated using an online survey, with particular focus on their burdens and anxieties. This survey was distributed to students within a 2-week period in April and May 2020. Ultimately, 1241 participants were included in the analysis. During the pandemic, $67.9 \%$ (65.3\% to $70.5 \%$ ) of the participants reported that they had volunteered. Furthermore, $88.9 \%(86.9 \%$ to $90.5 \%)$ stated that they were against compulsory recruitment in this context. Students who volunteered (committed students) had a significantly lower anxiety index than non-committed students. Additionally, students were more concerned about infecting other patients and relatives than themselves. Higher levels of anxiety were related to lower levels of commitment. A mandatory assignment during the pandemic was rejected by the students and does not seem to be necessary due to the large number of volunteers.

\section{INTRODUCTION}

At the beginning of the COVID-19 pandemic, knowledge about the virus was very limited. Early data from China suggested that healthcare workers had an increased risk of infection with the virus. ${ }^{1}$ Due to the spread of COVID-19 and the growing number of infected persons, the question arose as to how cover these shortages of staff within the healthcare sector. ${ }^{2}$ During the search for potential practitioners, two possible groups were identified namely retired healthcare workers and medical students. ${ }^{3}$ However, recruitment of retired staff was problematic, as it became clear that the risk of severe infection with COVID-19 increases with age. ${ }^{4}$

Therefore, medical students were identified as the preferred option to help the heavily burdened healthcare sector. ${ }^{3}$ This idea was not fundamentally new. There are two prominent examples, from the last century, when medical students were involved in fighting and overcoming a pandemic or epidemic. ${ }^{5}$ During the Spanish flu (1918), medical students at the University of Pennsylvania were recruited to take care of patients. ${ }^{6}$ Approximately four decades later (1952), medical students manually ventilated tracheostomised patients during the Danish polio epidemic. ${ }^{7}$
Based on these experiences, it is not surprising that several countries tried to accelerate the graduation of medical students along with intensified training of recently graduated physicians in order to treat patients with COVID-19. ${ }^{5}$ Currently, there is no research providing insights on anxiety level of committed medical students regarding potential viral infections during the pandemic. Therefore, we analysed this in the present study. We hypothesised that high individual levels of trait anxiety and low levels of empathy impact an individual's decision to volunteer during the pandemic. Furthermore, we reasoned that specific fear to become infected would impact willingness for commitment. Besides these intrinsic factors, we also analysed the financial situation of students (extrinsic factor).

\section{METHODS}

\section{Survey design}

During a 2-week period (25 May-07 June 2020), we assessed medical students in Germany using an online survey tool (EvaSys (https://www.evasys. de), Electric Paper Evaluationssysteme, Luneburg, Germany) provided by the Technical University of Munich. The questions assessed different aspects of the student's commitment during the COVID-19 pandemic. We systematically contacted all student representatives of medical faculties in Germany and asked them to share the link to the online survey with the students. Furthermore, we contacted the medical students via social media. Sample size calculation was based on the proportion of medical students who had voluntarily committed to help. As no prior information on this proportion was available, a hypothetical proportion of $50 \%$ was assumed. This assumption maximises the required sample size and results in the most conservative sample size estimation of $\mathrm{n}=383$ for a stipulated 95\% CI, 5\% error and a finite population size of approximately 100000 medical students in Germany.

\section{Analysed factors}

- Age, gender and location of medical school (demographic variables).

- Commitment, type of commitment and attitude towards a compulsory commitment (commitment-related variables).

- Anxiety items (anxious person, anxiety in the past month and anxious thoughts), empathy items (empathetic person, feelings of others 
influence my own feelings, ability to recognise other people's feelings and ability to distance own from others' feelings). Fear of self-infection, infecting other patients and people in one's personal environment (intrinsic motivational factors).

- Financial difficulties, financial distress, financial compensation and importance of financial compensation (extrinsic motivational factors).

- Mental stress, satisfaction of commitment and supervision during the commitment (mental and supportive factors).

- The students were directly asked if they experience their commitment as meaningful on a 10 -point Likert scale.

\section{Participants}

In total, 1407 medical students participated in the survey, hence approximately $1.4 \%$ of the German medical students responded to our questionnaire and 1241 were included in the final analysis. We excluded all participants who were in their final year of medical school $(n=163)$ (because commitment was compulsory in the final year of medical school in Germany) and participants who stated they are studying in Bremen or Brandenburg where there are no medical faculties $(n=2)$. We also excluded one participant who stated gender as diverse $(n=1$, no statistical inference possible). There was no significant difference in the commitment of students from northern ( $\mathrm{n}_{\text {north }}=485$ participants) and southern ( $\mathrm{n}_{\text {south }}=746$ participants) Germany $(\mathrm{p}>0.99)$.

\section{Index of anxiety}

Adapting the definition of anxiety from Asendorpf and Caspar, we developed three items for the purpose of measuring trait anxiety $^{8}$ : item 1: 'I consider myself as an anxious person'; item 2: 'I felt anxiety in the past month'; item 3: 'I often have anxious thoughts'.

These items were measured on a 10-point Likert scale, ranging from 'total disagreement' (1) to 'fully agree' (10). As a requirement of offsetting the answers to an index value, we premised an internal test consistency of Cronbach's alpha $>0.8$ and a selectivity $>0.3$ (item-scale correlation) between the respective questions. Those requirements were fulfilled for questions about anxiety (alpha: 0.81, selectivity: min. 0.64). The index was calculated using the following formula:

$$
\text { Index }=\frac{\sum_{i=1}^{3} \text { Question }_{i}-3}{27}
$$

Therefore, the index score takes values between the interval $(0,1) ; 1$ is the maximum and 0 the minimal index score. For measuring empathy by four items (item 1: 'I consider myself an empathetic person'; item 2: 'Feelings of others influence my own feelings'; item 3: 'I am able to recognise other people's feelings'; item 4: 'I am able to distance my own feelings from others' feelings'), we maximally scored a Cronbach's alpha $=0.62$, which did not meet our criteria of offsetting the answers to an index value.

\section{Statistical analysis}

Statistical analysis was performed using R V.3.6.0 (R core team (2019), Vienna, Austria). For categorical variables, Pearson's X ${ }^{2}$ test was used to assess group differences. Wilcoxon rank-sum test (two group comparison) and Kruskal-Wallis test (multiple group comparison) were used for quasi-steady variables (variables that have a sufficiently fine gradation to treat them as steady). For comparison of infection concerns, the Friedman test was used to account for paired samples. A Bonferroni correction was used to account for multiple tests (variables on infection concerns). To ensure an easy interpretation for the reader, $\mathrm{p}$ values were adjusted to the number of tests performed instead of adjusting the levels of significance. Adjusted $\mathrm{p}$ values are indicated by $\mathrm{P}_{\text {adj }}$. The $95 \%$ CIs are given in brackets.

\section{RESULTS}

In this survey, $75.8 \%$ of the participants were women $(n=941)$ and $24.2 \%$ were men $(n=300)$. Female students had a median age of 24 years (IQR of 22-27). Male students were slightly younger with a median age of 23 years (IQR of 24-26). All students included in the analysis had not yet started their final year of medical education. In Germany, the final year comprises a full-time clinical rotation at a hospital. Therefore, students in their final year were not available as additional human resources for the health system. A total of $67.9 \%$ (65.3\% to $70.5 \%)$ of the interviewed students declared a voluntary commitment during the COVID-19 pandemic. The proportion of male students who were committed was significantly higher with $75.0 \%(69.7 \%$ to $79.8 \%)$ vs $65.7 \%(62.5 \%$ to $68.7 \%)$ of female students $(\mathrm{p}=0.003)$ (figure 1A). A compulsory recruitment of medical students to assist during the COVID-19 pandemic was rejected by $88.9 \%$ (86.9\% to $90.5 \%$ ) of the students (figure 2 ).

When analysing the type of commitment, no significant genderrelated difference was observed. Both male and female students worked primarily in a clinical context (62.5\%) (figure 1B). Regional differences detected between federal states in Germany were not significant and did not suggest any geographical correlation. The proportion of voluntarily committed students ranged from $50 \%$ to $83.3 \%$ (figure $1 \mathrm{C}, \mathrm{D}$ ).

To address differences between committed and non-committed students, we hypothesised that intrinsic traits, namely anxiety and empathy, may influence the willingness to volunteer. Indeed, an anxiety index calculated from three items showed a respective relationship. Values of this index closer to 1 correspond to a high anxiety, index values closer to 0 correspond to a low anxiety. Non-committed medical students showed significantly higher index values (mean: 0.35 , SD: 0.25 ) than committed students (mean: $0.28, \mathrm{SD}: 0.21, \mathrm{p}<0.001$; figure $3 \mathrm{~A}$ ). In clinically committed students, the anxiety index correlated significantly with mental stress $(\mathrm{r}=0.37, \mathrm{p}<0.001$; figure $3 \mathrm{~B})$. Overall female students showed a significantly higher anxiety index (mean: 0.32 , SD: 0.23 ) than male students (mean: 0.23, SD: $0.20, \mathrm{p}<0.001$ ). Irrespective of age and gender, committed students experienced their commitment as meaningful, with a median rating of 7 (IQR of 5-8) measured on a Likert scale from 1 (low) to 10 (high). The level of satisfaction achieved by committed students showed a minor negative correlation with age $(\mathrm{r}=-0.18, \mathrm{p}<0.001)$. Overall, satisfaction was rated with a median of 6 (IQR of 5-8).

Besides intrinsic traits, we also hypothesised financial difficulties as extrinsic motivational factors influencing students' commitment. Indeed, financial difficulties occurred in $17.9 \%$ (15.8\% to $20.1 \%$ ) of all participants but were not significantly different between both groups $(\mathrm{p}=0.124$; figure $3 \mathrm{C})$. A total of $63.1 \%(59.8 \%$ to $66.4 \%)$ of those who volunteered received financial compensation for the work. However, the importance of payments was rated with a median of 2 (with IQR of 1-6).

We also addressed concerns about infections with COVID19. Students reported being least concerned with becoming infected with the virus themselves, followed by concerns about infecting patients. The students showed major worries about infecting closely related persons (figure 4A). Non-committed students showed significantly higher concerns about infecting themselves $\left(\mathrm{P}_{\text {adj }}=0.006\right)$ and people in their personal environment $\left(\mathrm{P}_{\text {adj }}<0.001\right)$ compared with committed students. 

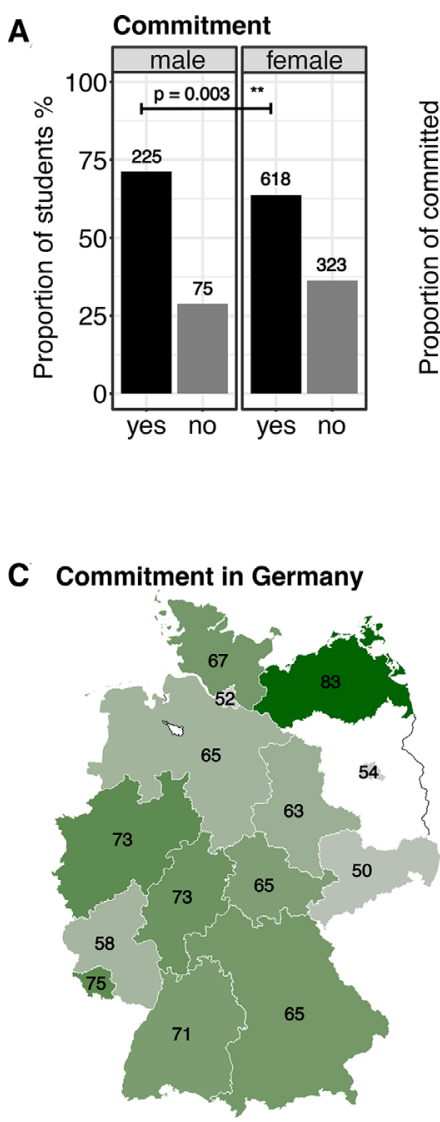

Proportion of students in \% $5060 \quad 70 \quad 80$

\section{B Type of commitment}

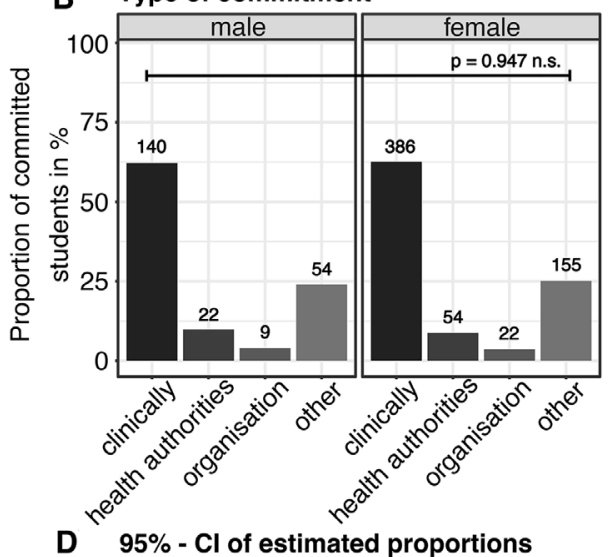

D $95 \%-\mathrm{Cl}$ of estimated proportions

\begin{tabular}{|c|c|}
\hline 254 & Baden Wurttemberg \\
\hline 241 & Bavaria \\
\hline 13 & Berlin \\
\hline 29 & Hamburg \\
\hline 171 & Hessen \\
\hline 6 & Mecklenburg-West Pomerania \\
\hline 20 & Lower Saxony \\
\hline 221 & North Rhine Westphalia \\
\hline 57 & Rhineland Palatinate \\
\hline 20 & Saarland \\
\hline 30 & Saxony \\
\hline 60 & Saxony Anhalt \\
\hline 73 & Schleswig-Holstein \\
\hline 46 & Thuringia \\
\hline${ }^{0}$ Pro & \\
\hline
\end{tabular}

Figure 1 (A) Relative proportion of medical students in Germany with a voluntary commitment. Numbers above columns indicate the absolute number of students in each group. Test for statistical significance was performed using the $\mathrm{X}^{2}$ test. (B) Relative proportion of different types of commitment. The type 'organisation' refers to organisational work in the medical faculty. Test for statistically significant differences between male and female students was performed using the $\mathrm{X}^{2}$ test. (C) Estimation of the proportion of committed students in German federal states. In the states Bremen and Brandenburg, there are no medical faculties. The number in each state refers to the proportion in $\%$ of voluntarily committed students in each state. (D) Visualisation of the $95 \% \mathrm{Cls}$ of the estimated proportions of committed students in German states. White vertical bars depict the estimated proportions in $\%$, black boxes refer to the $\mathrm{Cl}$, numbers at the beginning of each bar indicate the number of students questioned in the corresponding state. n.s., not significant.

Concerns about infecting other patients did not significantly differ between the two groups $\left(\mathrm{P}_{\text {adj }}=0.477\right)$. However, concerns about infecting other patients or related persons were significantly lower in men $\left(\mathrm{P}_{\text {adj }}<0.001\right.$ and $\left.\mathrm{P}_{\text {adj }}<0.001\right)$, while concerns about self-infection did not differ between both sexes $\left(\mathrm{P}_{\text {adj }}=0.184\right)$. Furthermore, concerns about infecting other patients or related persons significantly declined with age $\left(P_{\text {adj }}=0.007\right.$ and $P_{\text {adj }}=0.017$ ) (figure 4B,C). Committed students rated the sufficiency of supervision (to discuss concerns) with a median of 6 (IQR of 4-8). Supervision time to discuss medical issues was rated with 5 (median, IQR of 3-7). Female students rated both items significantly lower than male students $\left(\mathrm{P}_{\text {con- }}\right.$ $=0.039$ and $P_{\text {medical issues }}=0.044$ ).

Based on self-disclosure, the overall infection rate of the students was estimated to be $1.5 \%$ (0.9\% to $2.4 \%$ ) (figure $4 \mathrm{D}$ ).

\section{DISCUSSION}

This study investigated the voluntary commitment of medical students in Germany to actively engage in the fight against COVID-19. We can provide insights into how a pandemic and a possible commitment in fighting the pandemic impacts lives, thoughts and feelings of medical students. Furthermore, we could show that most medical students committed voluntarily and refused a compulsory commitment. Interestingly, students were less concerned about their own infection with COVID-19, than about the infection of patients or relatives. Higher levels of anxiety were related to lower levels of commitment. The students mostly stated that they benefited from volunteering, that they were satisfied and had sufficient opportunities to talk about their experiences to supervisors. Overall, less than $2 \%$ of all participants declared that they had been infected with COVID-19.

University students usually present a high incidence rate of psychological disorders. ${ }^{9}$ Due to the current situation, it has been speculated that the incidence rates will increase further. ${ }^{10}$ In a recent study, assessing mental health of Chinese medical college students, elevated levels of anxiety were associated with factors strongly related to COVID-19. These factors inter alia included having contact with a COVID-19-diagnosed patient. ${ }^{11}$ During the current pandemic, in addition to anxiety, a rise in psychological symptoms such as perceived stress and depression has been recorded in the general population. ${ }^{12}$ Our study confirms these findings: we found a variety of concerns and fears regarding the pandemic and anxiety in general seems 


\section{Compulsory commitment}

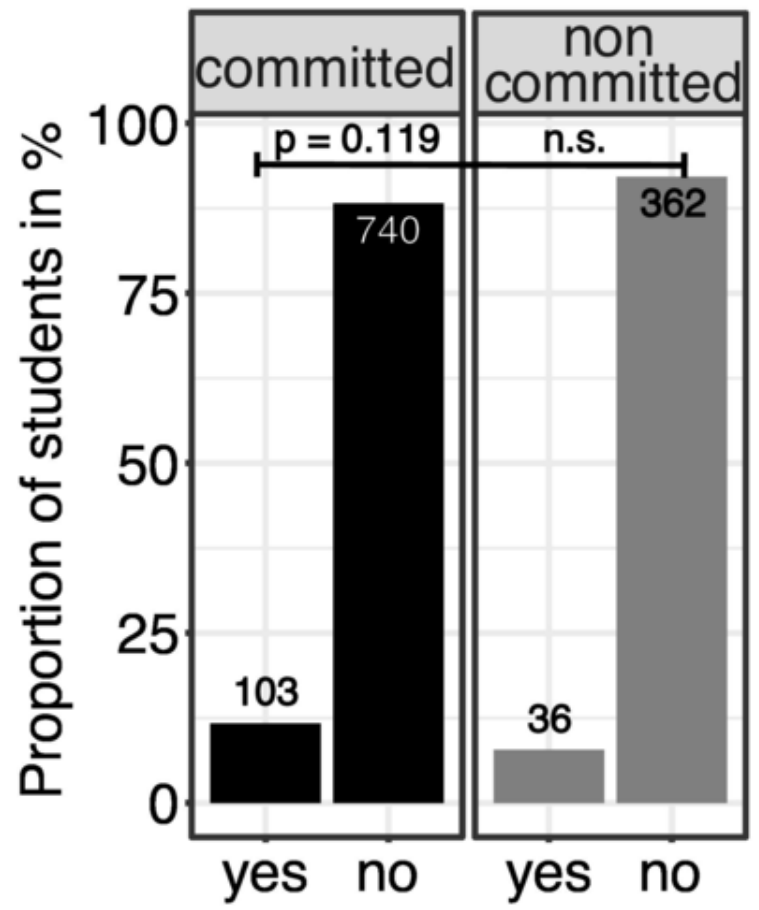

Figure 2 Opinion of German medical students concerning an obligatory commitment during the pandemic in relative numbers. Numbers above columns indicate the absolute number of students in each group. Test for statistical significance between committed and noncommitted students was performed using the $\mathrm{X}^{2}$ test. n.s., not significant.

to play a significant role for volunteering in our analysed population.

Maner and Schmidt ${ }^{13}$ previously showed a correlation of high levels of trait anxiety with avoidance of risky situations in young adults. Our results support this behaviour. We found an inverse connection between anxiety and commitment: the level of trait anxiety was directly connected with volunteering rate and fear about the risk of infection. In a survey that analysed the psychological well-being of 1000 Greek students from various disciplines, students showed a significant increase in anxiety and depression during the pandemic. The level of anxiety was dependent on various factors, such as socioeconomic background, prolonged study duration, changes in everyday life and social structure during the pandemic. ${ }^{11}$ Our data suggest that gender seems to be a predictive factor. We found significantly higher levels of anxiety in female when compared with male medical students. The level of anxiety was especially high in non-committed students. Interestingly, many studies have reported female gender as a predictive factor for higher levels of depression and anxiety, potentially due to a co-occurrence of additional stress factors (eg, childcare, lower socioeconomic background). ${ }^{14}$

It has been speculated that the psychological effects on healthcare workers related to the current pandemic are driven by numerous factors. ${ }^{15}$ This includes lack of beneficial therapies, shortages of healthcare capacities, limited personal protective equipment, uncertainty of the actual situation, limited information about the virus and uncertainty about the length of the pandemic. ${ }^{1516}$ In extreme situations, when more resources are required than available, psychological strain can escalate. Then, decision-makers face an ethical dilemma regarding the question of who can be treated with currently available resources. ${ }^{17} 18$ This might be aggravated in early stages of a pandemic without having evidence-based guidance. Therefore, the crucial question seems to be how to mitigate psychological distress and how to deal with challenging ethical questions. Based on experiences from the 2003 severe acute respiratory syndrome outbreak and the early stage of COVID-19, psychological support should be offered to affected groups. ${ }^{15} 19$ Establishing regular meetings with supervisors also helped to mitigate levels of anxiety and stress. ${ }^{15} 20$ Medical schools are aware of this need and established, for instance, checking-in emails, online meeting platforms and discussion rounds. ${ }^{21}$ Our study shows that medical schools across Germany fulfilled these imminent needs. The participants in our survey reported having enough time to discuss their situation or problems and seek advice. So, the basis for successful voluntary work of students to fight the pandemic seems to be given.

A recent study from China reported that approximately 90\% of respondents exhibited discriminatory attitudes toward people and regions associated with the COVID-19 outbreak. ${ }^{22}$ It is well known that perceived societal stigma has a negative impact on mental health. ${ }^{23}$ The societal stigma of infectious diseases is not completely new. It has also been noted in the context of HIV among gay and bisexual men. ${ }^{24}$ In the ' 80 s and '90s of last century, the stigmatisation was based on anxiety, uncertainty, and lack of information and treatment. ${ }^{24} 25$ Similar experiences of stigmatisation might be associated with COVID-19 today, recently published data revealed a tendency of COVID-19 stigmatisation. ${ }^{23}$ In the past, it has been assumed that extensive information campaigns and goal-oriented lessons in medical schools would overcome this kind of discrimination. ${ }^{25}$ Nevertheless, a considerable proportion of medical students and physicians still demonstrate their fears when interacting with patients with HIV. $^{26}{ }^{27}$ It is well known that fears and discrimination jeopardise patient-doctor relationships, leading to poorer care and worse outcomes. ${ }^{26} 27$ Therefore, it is of great importance that medical educators are aware of potential stigmatisation, avoiding mistakes of the past by using lesson learnt approaches. In patients with HIV/AIDS, it has been proposed that medical educators must be prepared to help students overcome prejudice and increase their capacity for empathy toward patients with AIDS. ${ }^{28}$ This strategy seems to be applicable to patients with COVID-19. Furthermore, this strategy might help to prevent ethical debates (known from AIDS/HIV) about physicians' rights to refuse treatment. ${ }^{28}$

Another solution seems to be volunteerism. It is known that medical students who had contact to stigmatised groups of people or patients showed decreased levels of prejudice and fear. ${ }^{10}$ Even though we found high levels of satisfaction and proudness when volunteering during the COVID-19 pandemic in our study, COVID-19 also leads to new ethical dilemmas for volunteers. Other studies reported that many students reported moral distress when watching patients being isolated from loved ones or when feeling distant from patients while wearing personal protective equipment. ${ }^{29}$ Furthermore, students felt not only anxious about COVID-19 but also vulnerable. ${ }^{23}$ The anxieties are enhanced in volunteers working on the pandemic's front lines. It seems to be important for medical students to have the opportunity to discuss such concerns with supervisors. ${ }^{30}$ Based on the results of our survey, medical students across Germany stated that they had good opportunities for such interactions. The supervisions also offered the opportunity to discuss bioethical issues that previously seemed theoretical, namely, rationing 

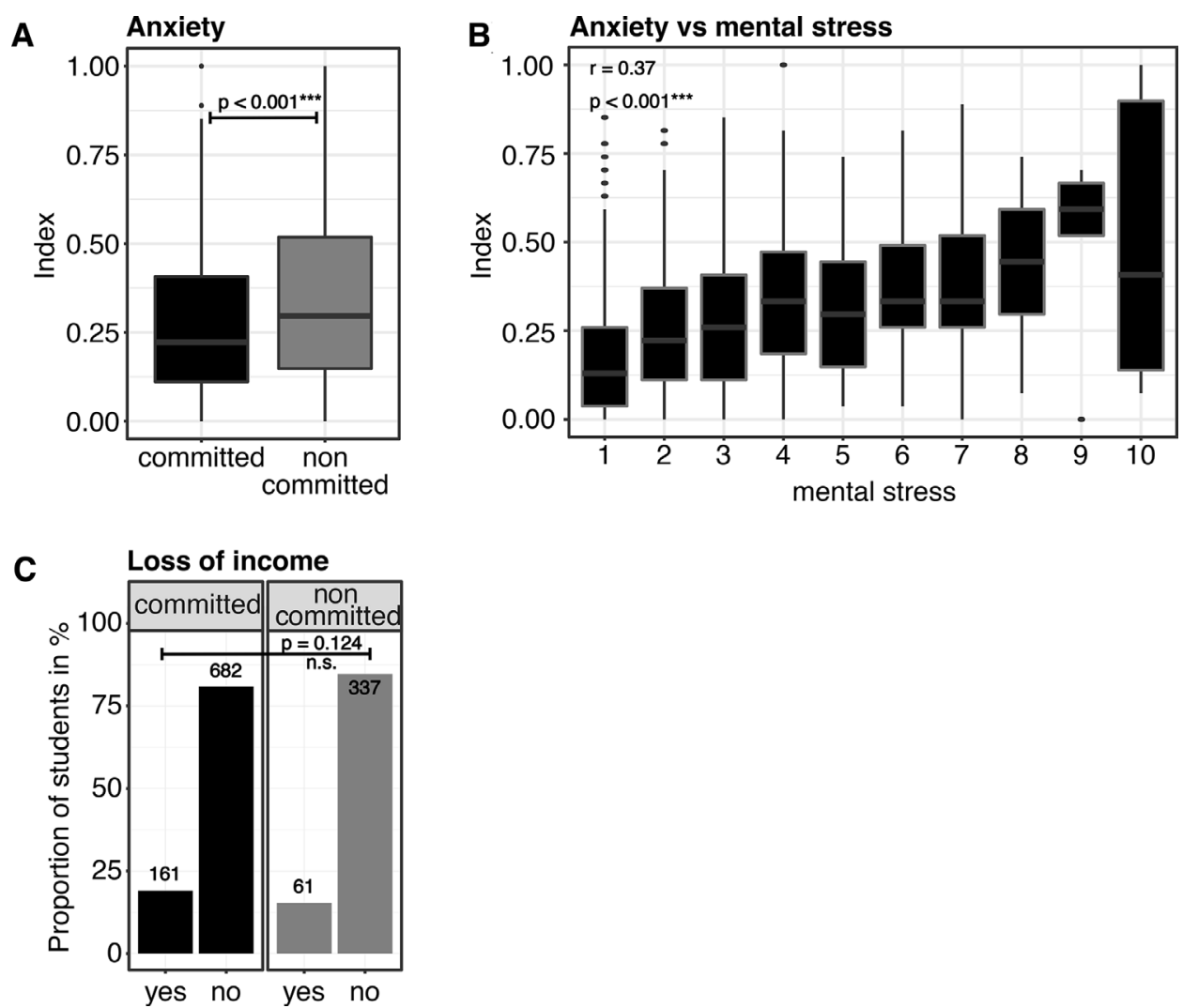

Figure 3 (A) Comparison of the anxiety index of committed versus non-committed students. Calculation of the index is given in the Methods section. Test for significant differences was determined using the Wilcoxon rank-sum test. (B) Anxiety depending on mental stress of committed medical students. (C) Relative proportion of medical students who faced a loss of income during the COVID-19 pandemic. Test for statistical significance between committed and noncommitted students was performed using the $\mathrm{X}^{2}$ test. n.s., not significant.

and futility of care. Medical educators can teach students about ways of allocating scarce resources and improving end-of-life care. $^{29}$

It is also important to take care of students who cannot volunteer during the COVID-19 pandemic due to personal health issues. These students often reported high levels of guilt that others had to step in; they frequently complained about disappointment or frustration about not being able to help. ${ }^{29}{ }^{30}$ However, students who could not or did not want to work directly with patients with COVID-19 could be very valuable in other functions. A report from Canada showed that an interaction of seniors with students via video call significantly reduces the impact of loneliness. ${ }^{31}$ Students who participated in this project also regained self-esteem and purpose in a social role. They had better mental health status and reported lower levels of helplessness. ${ }^{31}$ Alternatively, medical students could support healthcare departments or get involved in the organisation of online medical education. ${ }^{5}$

In our survey, we found that medical students felt high levels of proudness and satisfaction by volunteering during the pandemic. However, current research also indicates that the current pandemic will have an impact on their future careers. Byrnes $e a^{32}$ reported that approximately one-fifth of surveyed medical students in the USA (1668 medical students participate in this study, the survey included all 150 American Association of Medical Colleges medical schools in the USA, Hawaii and Alaska) assume that COVID-19 will affect their study duration and choice of specialty. Many students are raising concerns that they cannot explore specialisations or obtain recommendation letters. Since we do not know how the
COVID-19 pandemic will continue, we should proceed in the spirit of Zuger and Miles ${ }^{33}$ : 'Medicine is an inherently moral enterprise, the success and future of which depend to a great extent on the integrity of individual professionals as they face the duties the calling of healer entails.' Based on the currently available evidence of medical students during the COVID-19 pandemic and due to the results of our survey, we have the justified hope that the new generations of doctors are strongly committed to the people.

Our study has some limitations:

- Data collection during a defined time reflects the impressions at this specific time point. A dramatic increase in infected patients or the availability of a vaccine/therapy may have an impact on these results.

- Since the survey was done in Germany, the data are limited to German medical students. Students from other disciplines or other countries may show different behaviours.

- After our systematic consultation of the student representatives of German medical faculties, we had no influence on further distribution of the link. This may lead to minor estimation biases. However, we do not see significant differences in the proportion of committed students between northern and southern Germany.

- We did not use previously proposed measures for anxiety ${ }^{34}$ in our study. Therefore, it might be possible that exploring anxiety by using these previously described instruments might result in different findings. 
A) Concerns about infection

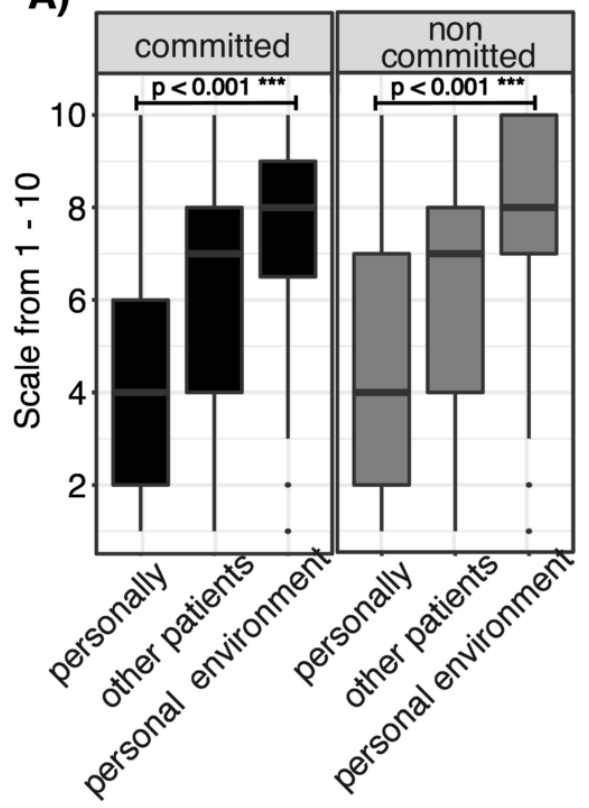

C) Concerns about infecting personal environment vs age

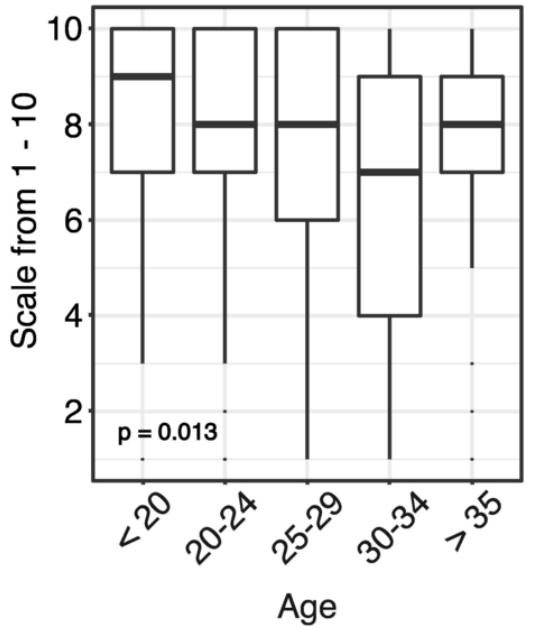

B) Concerns about infecting other patients vs age
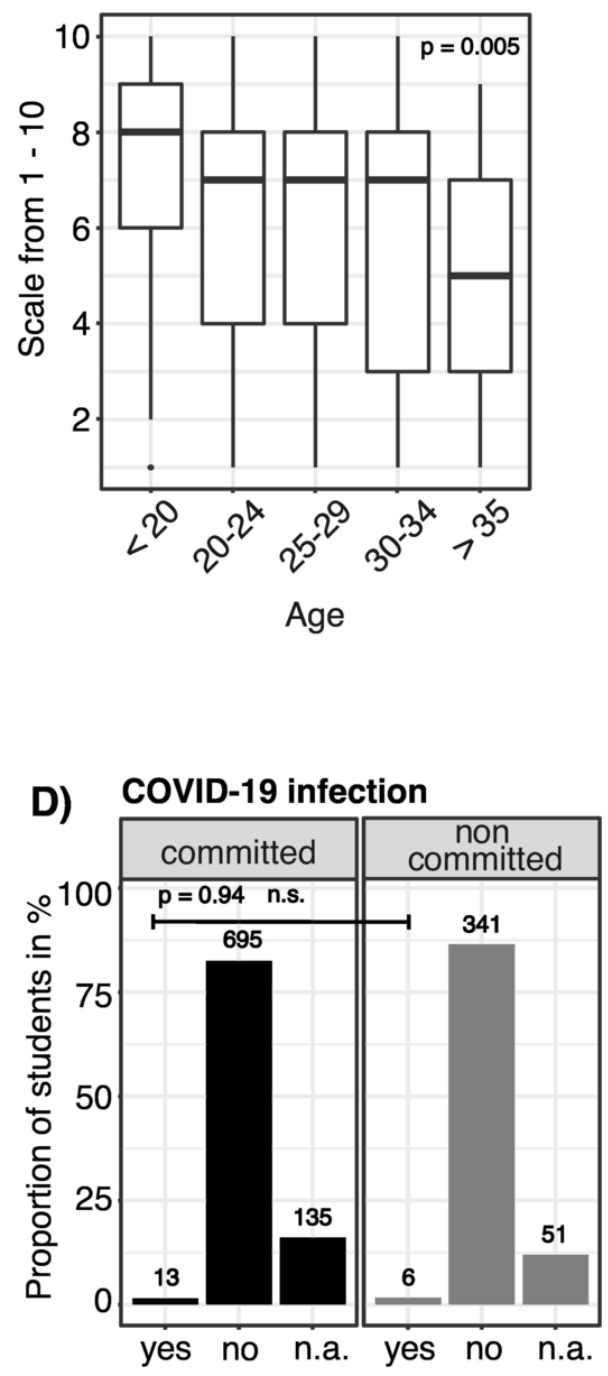

Figure 4 Risk of infection. (A) Concerns of committed and non-committed medical students of being infected themselves, of unwillingly infecting other patients and people of their personal environment. Measured on a Likert scale from 1 (low fear) to 10 (high fear). Friedmann test was used to test for significant differences between the concern variables. $\mathrm{P}$ values were corrected by the Bonferroni method. (B) Concern of medical students about infecting other patients depending on age. Differences between the age groups are tested for significance by the Kruskal-Wallis test. P values were corrected by the Bonferroni method. (C) Concerns of medical students about infecting other people in their personal environment depending on age. Differences between the age groups are tested for significance by the Kruskal-Wallis test. P values were corrected by the Bonferroni method. (D) Relative proportion in \% of students, which have been infected with COVID-19 based on self-disclosure. Test for statistical significance between committed and non-committed students was performed using the $\mathrm{X}^{2}$ test. n.s., not significant, n.a., not available.

\section{CONCLUSION}

The results of this study suggest that most German medical students who are working on the front lines of the pandemic have done so voluntarily. They reported high levels of satisfaction and sufficient psychological support from supervisors. Furthermore, they reject a compulsory commitment for students to help fight the pandemic. Higher levels of anxiety were related to lower levels of commitment. Their infection rates were comparable with that of the German population. Ultimately, their biggest fear was to infect other patients, relatives or friends.
Contributors LM, MvdL, FK and JH designed the study. LM, BL and KD collected the data. LM performed the statistical analysis. All authors were involved in the interpretation of the data. LM and JH wrote the manuscript. MvdL, FK, BL and KD were involved in drafting the manuscript and revising it critically for important intellectual content. All authors read and approved the final manuscript.

Funding FK received funding from the European Union's Horizon 2020 (grant number: 754462). The remaining authors have not declared a specific grant for this research from any funding agency in the public, commercial or not-for-profit sectors.

Competing interests $\mathrm{JH}$ is employee of Sandoz/Hexal. His occupation neither affected on the planning and execution of the study nor on the manuscript. All other authors declare no conflict of interest. 
Patient consent for publication Not required.

Ethics approval The survey was performed in accordance with the Declaration of Helsinki. It was approved by the Institutional Review Board of the Ludwig-Maximilians University of Munich (20-458 KB). All participants were informed about the purpose, objectives and handling of the data that were captured in the questionnaire. All participants gave informed consent.

Provenance and peer review Not commissioned; externally peer reviewed.

Data availability statement Data are available upon reasonable request.

Open access This is an open access article distributed in accordance with the Creative Commons Attribution Non Commercial (CC BY-NC 4.0) license, which permits others to distribute, remix, adapt, build upon this work non-commercially, and license their derivative works on different terms, provided the original work is properly cited, appropriate credit is given, any changes made indicated, and the use is non-commercial. See: http://creativecommons.org/licenses/by-nc/4.0/.

\section{REFERENCES}

1 Chang D, Xu H, Rebaza A, et al. Protecting health-care workers from subclinical coronavirus infection. Lancet Respir Med 2020;8(3):e13.

2 Majorski DS, von Plessen CM, Scheffer C. Coronakrise: Medizinstudierende helfen Lassen. Dtsch Arztebl 2020;117(21).

3 Corona: Spahn verspricht Krankenhäusern finanzielle Hilfe. Available: https://www. aerzteblatt.de/nachrichten/111050/Corona-Spahn-verspricht-Krankenhaeusernfinanzielle-Hilfe [Accessed 09 Dec 2020].

4 Wang R, Pan M, Zhang X, et al. Epidemiological and clinical features of 125 hospitalized patients with COVID-19 in Fuyang, Anhui, China. Int J Infect Dis 2020;95:421-8.

5 Miller DG, Pierson L, Doernberg S. The role of medical students during the COVID-19 pandemic. Ann Intern Med 2020;173(2):145-6.

6 Richter-Kuhlmann E. Hausarzt Novelle der Approbationsordnung: Ein Sieg für die Studierenden. Dtsch Arzteb/ 2020;109:A-1002/B-866/C-858.

7 Starr I. Influenza in 1918: recollections of the epidemic in Philadelphia. 1976. Ann Intern Med 2006;145(2):138-40.

8 Asendorpf J, Caspar F. Angst. In M. A. Wirtz (Hrsg.), Dorsch - Lexikon der Psychologie.

9 Bruffaerts R, Mortier P, Kiekens $G$, et al. Mental health problems in college freshmen: prevalence and academic functioning. J Affect Disord 2018;225:97-103.

10 Odriozola-González P, Planchuelo-Gómez Álvaro, Irurtia MJ, et al. Psychological effects of the COVID-19 outbreak and lockdown among students and workers of a Spanish university. Psychiatry Res 2020;290:113108.

11 Cao W, Fang Z, Hou G, et al. The psychological impact of the COVID-19 epidemic on college students in China. Psychiatry Res 2020;287:112934

12 Wang C, Pan R, Wan X, et al. Immediate psychological responses and associated factors during the initial stage of the 2019 coronavirus disease (COVID-19) epidemic among the general population in China. Int J Environ Res Public Health 2020;17(5):1729.

13 Maner JK, Schmidt NB. The role of risk avoidance in anxiety. Behav Ther 2006:37(2):181-9.

14 Fancourt D, Steptoe A, Bu F. Trajectories of anxiety and depressive symptoms during enforced isolation due to COVID-19 in England: a longitudinal observational study. Lancet Psychiatry 2021;8(2):141-9.
15 Wu PE, Styra R, Gold WL. Mitigating the psychological effects of COVID-19 on health care workers. CMAJ 2020:192(17):E459-60.

16 Bakioğlu F, Korkmaz O, Ercan H. Fear of COVID-19 and positivity: mediating role of intolerance of uncertainty, depression, anxiety, and stress. Int I Ment Health Addict 2020:1-14.

17 Behrens KG, University of the Witwatersrand, Johannesburg. Clinical ethical challenges in the Covid-19 crisis in South Africa. Wits I Clin Med 2020;2(SI):29-32.

18 Kannampallil TG, Goss CW, Evanoff BA, et al. Exposure to COVID-19 patients increases physician trainee stress and burnout. PLoS One 2020;15(8):e0237301.

19 Maunder R, Hunter J, Vincent L, et al. The immediate psychological and occupational impact of the 2003 SARS outbreak in a teaching hospital. CMAJ 2003;168(10):1245-51.

20 Styra R, Hawryluck L, Robinson S, et al. Impact on health care workers employed in high-risk areas during the Toronto SARS outbreak. J Psychosom Res 2008;64(2):177-83.

21 Chandratre S. Medical students and COVID-19: challenges and supportive strategies. J Med Educ Curric Dev 2020:7.

22 He J, He L, Zhou W. Discrimination and social exclusion in the outbreak of COVID-19. Int J Environ Res Public Health 2020;17:2933.

23 Sun S, Goldberg SB, Lin D, et al. Psychiatric symptoms, risk, and protective factors among university students in quarantine during the COVID-19 pandemic in China. Global Health 2021:17(1):15.

24 Stangl AL, Lloyd JK, Brady LM, et al. A systematic review of interventions to reduce HIV-related stigma and discrimination from 2002 to 2013: how far have we come? J Int AIDS Soc 2013;16(3 Suppl 2):18734

25 Alawad M, Alturki A, Aldoghayyim A, et al. Knowledge, attitudes, and beliefs about HIVIAIDS and people living with HIV among medical students at Qassim university in Saudi Arabia. Int J Health Sci 2019;13(5):22-30.

26 Varas-Díaz N, Rivera-Segarra E, Neilands TB, et al. HIV/AIDS and intersectional stigmas: examining stigma related behaviours among medical students during service delivery. Glob Public Health 2019;14(11):1598-611.

27 Ledda C, Cicciù F, Puglisi B, et al. Attitude of health care workers (HCWs) toward patients affected by HIV/AIDS and drug users: a cross-sectional study. Int I Environ Res Public Health 2017:14(3):284.

28 Kopacz DR, Grossman LS, Klamen DL. Medical students and AIDS: knowledge, attitudes and implications for education. Health Educ Res 1999;14(1):1-6.

29 Gallagher TH, Schleyer AM. "We Signed Up for This!" - Student and Trainee Responses to the Covid-19 Pandemic. N Engl J Med 2020;382(25):e96.

30 O'Byrne L, Gavin B, McNicholas F. Medical students and COVID-19: the need for pandemic preparedness. J Med Ethics 2020;46(9):623-6.

31 Zheng DJ, Li HO-Y. Intergenerational benefits of student Volunteerism in medical education. Acad Med 2021;96(2):e9.

32 Byrnes YM, Civantos AM, Go BC, et al. Effect of the COVID-19 pandemic on medical student career perceptions: a national survey study. Med Educ Online 2020;25(1):1798088.

33 Zuger A, Miles SH. Physicians, AIDS, and occupational risk. historic traditions and ethical obligations. JAMA 1987;258(14):1924-8.

34 Julian LJ. Measures of anxiety: State-Trait anxiety inventory (STAI), Beck anxiety inventory (BAI), and hospital anxiety and depression Scale-Anxiety (HADS-A). Arthritis Care Res 2011;63(S11):S467-72. 